\title{
SOBRE A TEORIA DO CONHECIMENTO NAS PASSAGENS DE WALTER BENJAMIN - SUJEITO EM DESAGREGAÇÃO
}

\author{
On the theory of Knowledge in Walter Benjamin's \\ Arcades Project - subject in disintegration
}

Sobre la teoria del conocimiento en los Pasajes de Walter Benjamin - sujeto en desagregación

\author{
Manuela Sampaio de Mattos' \\ Associação Psicanalítica de Porto Alegre (APPOA)
}

\section{Resumo}

O presente artigo apresenta a distinta teoria do conhecimento proposta por Walter Benjamin em seu projeto das Passagens. Tal proposta já encontra suas origens em seus textos de juventude, principalmente em seu Sobre o programa de uma filosofia vindoura. Levando isso em conta, articulamos os dois momentos da obra de Benjamin para demonstrar que essa nova teoria materialista, dialética e imagética do conhecimento pressupõe um conceito mais alto de experiência, assim como uma crítica contundente ao sujeito do conhecimento que se encontra em vias de desagregação. Para nos aprofundarmos na proposição benjaminiana, adentramos a importante topografia conceitual presente nas Passagens, passando pelos temas da linguagem, do sonho, do despertar e das imagens dialéticas.

Palavras-chave: Conhecimento. Sujeito. Passagens. Sonho. Imagens dialéticas.

\footnotetext{
Doutora em Filosofia pela Pontifícia Universidade Católica do Rio Grande do Sul (PUCRS). Psicanalista na Associação Psicanalítica de Porto Alegre (APPOA). Porto Alegre, RS, Brasil. ORCID: http://orcid.org/o0oo-0003-4721-0841.E-mail: manuelasmattos@gmail.com
} 


\begin{abstract}
The present article presents the distinguished theory of knowledge proposed by Walter Benjamin in his Arcades Project. Such a proposal already finds its origins in his youth texts, especially in his On the program of a coming philosophy. Taking this into account, we articulate the two moments of Benjamin's work to demonstrate that this new materialistic, dialectical and visual theory of knowledge presupposes a higher concept of experience, as well as a compelling critique of the subject of knowledge that is in the process of disintegrating. In order to deepen ourselves in the Benjaminian proposition, we enter the conceptual topography present in the Arcades Project, going through the themes of language, dream, awakening and dialectical images.
\end{abstract}

Keywords: Knowledge. Subject. Arcades. Dream. Awakening. Dialectical images.

\title{
Resumen
}

Este artículo presenta la distinta teoría del conocimiento propuesta por Walter Benjamin en su proyecto de los Pasajes. Esta propuesta ya tiene su origen en sus textos juveniles, especialmente en su programa de una filosofía venidera. Teniendo esto en cuenta, articulamos los dos momentos del trabajo de Benjamin para demostrar que esta nueva teoría materialista, la dialéctica e imagetica del conocimiento supone un concepto más elevado de experiencia, así como una crítica contundente al sujeto del conocimiento que se encuentra en proceso de desagregación. Para profundizar la proposición benjaminiana, entramos en la importante topografía conceptual presente en los Pasajes, a través de los temas del lenguaje, el sueño, el despertar y las imágenes dialécticas.

Palabras clave: Conocimiento. Sujeto. Pasajes. Sueño. Imágenes dialécticas.

\section{Introdução: Dialética da história cultural}

Com o seu trabalho das Passagens (Passagen-Werk), Walter Benjamin procurou colocar em prática uma filosofia material da história de caráter visual, articulando diferentes áreas do conhecimento para levar a cabo o seu desejo de conquistar para uma época a concretude extrema², aos moldes do que realizara com o seu Rua de mão única [Einbanstraße]. A partir do cenário

2 BENJAMIN, Walter. [Carta] 15 mar. 1929. Berlin [para] Scholem. In: Gesammelte Schriften. v. 2. 1982. p. 1090. 
urbano parisiense, Benjamin se ocupou de integrar em sua filosofia certos fenômenos que se apresentam concretamente a ele naquele seu contexto de vida, tomando-os como ur-fenômenos materiais, capazes de constituir o material adequado para a interpretação do presente, do passado recente e do futuro. A arquitetura de Paris, principalmente as passagens parisienses, foram o material no qual Benjamin se inspirou para começar a construir o seu projeto. Esses monumentos arquitetônicos que foram as passagens the permitiram pensar nas concepções mais cruciais que entram em ação em seu então novo projeto filosófico, dentre eles o conceito de imagens dialéticas, imagens de sonho e de desejo, inconsciente do coletivo, despertar, fantasmagoria, dialética na imobilidade, agora da cognoscibilidade, dentre outros.

No Konvolut $N$ deste seu projeto inacabado das Passagens, que leva o título "Teoria do conhecimento, teoria do progresso", Benjamin erigiu a coluna que estrutura esse seu projeto filosófico. Neste arquivo $\mathrm{N}$, encontramos suas arrojadas intenções metodológicas para a construção de uma diversa teoria do conhecimento - dialética, histórica e materialista - que, aos moldes dos textos de seus textos de juventude, deveria levar em conta um conceito diverso de experiência daquele concebido pelo idealismo alemão e, com isso, aspirar pela transposição da dicotomia sujeito-objeto afim de assim também traçar uma nova teoria do conhecimento. Iniciemos pela análise de um recorte acerca da metodologia, apresentado em um fragmento ainda pertencente à fase inicial do projeto:

Pequena proposta metodológica para a dialética da história cultural. É muito fácil estabelecer dicotomias para cada época, em seus diferentes 'domínios', segundo determinados pontos de vista: de modo a ter, de um lado, a parte 'fértil', 'auspiciosa', 'viva' e 'positiva', e de outro, a parte inútil, atrasada e morta de cada época. Com efeito, os contornos da parte positiva só se realçarão nitidamente se ela for devidamente delimitada em relação à parte negativa. Toda negação, por sua vez, tem o seu valor apenas como pano de fundo para os contornos do vivo, do 
positivo. Por isso, é de importância decisiva aplicar novamente uma divisão a esta parte negativa, inicialmente excluída, de modo que a mudança de ângulo de visão (mas não de critérios!) faça surgir novamente, nela também, um elemento positivo e diferente daquele anteriormente especificado. E assim por diante ad infinitum, até que todo o passado seja recolhido no presente em uma apocatástase histórica ${ }^{3}[\mathrm{~N}$ 1a, 3].

"Dialética da história cultural" poderia ser outro dos títulos do projeto das Passagens. O estabelecimento da proposta metodológica para o desenvolvimento de tal projeto se torna central, e aparece então como que uma petição de princípios para que os desígnios de sua teoria do conhecimento se concretizem. Nesse fragmento, Benjamin fala do quanto pode ser fácil estabelecer - e quem estabelece é o sujeito do conhecimento - as dicotomias de cada época, o que invariavelmente dependerá de um certo ponto de vista, ou seja, de uma determinada posição de observação e de discurso situada no contexto da experiência. É desde essa posição que poderão ser determinadas tanto a parte positiva quanto a negativa de cada época. Aquilo que resta afirmado como negação existe para, ao mesmo tempo, sustentar e realçar a afirmação do positivo, "do vivo", em detrimento do que resta escondido do negativo, da parte "morta". Por conseguinte, Benjamin sugere que é de importância decisiva, para a dialética que está propondo, que se retorne à parte negativa excluída em favor da positiva, e que se aplique novamente uma divisão dessa parte negativa para que, assim, se instaure uma mudança no ângulo de visão, o qual seria capaz de fazer surgir um elemento positivo diverso do anterior e assim por diante.

Esse percurso deveria ser percorrido infinitamente, até que ocorresse a admissão de todas as almas no paraíso. Ao utilizar o termo apocatástase, é possível afirmar que Benjamin também está colocando em cena a sua teoria da linguagem lançada em "Sobre a linguagem em geral e sobre a

3 BENJAMIN, W. Passagens. Belo Horizonte: UFMG, 2018, p. 762-763. 
linguagem do homem", onde trabalha a dialética entre a linguagem de Deus e linguagem do ser humano, qual seja, a da queda. Se a linguagem do ser humano é a linguagem da queda, ao tratarmos das dimensões do conceito em filosofia, estamos ao mesmo tempo lidando sempre com essa outra camada que resta excluída da linguagem assertiva ao dizermos "eu penso", e com isso desdobrarmos todos os demais predicativos resultantes dessa afirmação. É como se a cada palavra lançada ao mundo restasse um mundo correspondente lançado ao risco de exclusão e de esquecimento, e com esse mundo muitas almas estariam sentenciadas a não fazerem parte do paraíso a partir da queda do ser humano na linguagem dos símbolos. Ao propor um retorno incessante à negatividade, Benjamin está sugerindo que sempre retornemos aos restos daquilo que constituíram e sobraram das escolhas cognoscentes, assim reconhecendo que aquilo que é afirmado positivamente se trata de um efeito resultante de decisões tomadas em um contexto sempre mais complexo e constituinte do que podemos dar conta ao performatizarmos com a linguagem.

A proposta metodológica de lidar com o que sobrou de uma operação intelectual, de retornar a um ponto que aparentemente - e apenas aparentemente - estaria superado, não significa a repetição incessante do mesmo, mas a interrupção da continuidade de uma série sempre igual de escolhas determinadas pelos desígnios do autorreferente sujeito do conhecimento, e isso se dá através da instauração da chance para que o novo advenha no pensamento através dos próprios restos produzidos pelo cogito quando esse tenta se afirmar sem contradições. Não é porque uma escolha racional de excluir a negação fora feita para enaltecer os contornos do positivo que esse conteúdo excluído deixará de surtir efeitos no percurso mesmo do conhecimento. Benjamin está atento a isso e quer recuperar esta dimensão excluída, tanto para o próprio percurso do pensamento filosófico quanto para fazer justiça aos restos destes acontecimentos históricos. A camada excluída aparece fragmentariamente e de forma ínfima, por isso o seu uso no retorno ao negativo precisa ser concebido a partir de uma metodologia muito específica que permita aos restos falarem por si mesmos. São cifras 
de uma realidade já não mais presente, mas se atualizam temporal e dialeticamente, através de imagens que compõem uma imagerie inconsciente de si e inconsciente para o sujeito do conhecimento. Notemos que a relação entre o passado e o presente carrega um sentido próprio de temporalidade para a filosofia benjaminiana, e que a relação entre o ocorrido e o agora de sua cognoscibilidade torna-se, por isso, radicalmente dialética.

\section{Sobre o programa de uma filosofia por vir}

A proposta benjaminiana de uma distinta teoria do conhecimento já está presente em seu texto de juventude "Sobre o programa da filosofia vindoura", de 1918) ${ }^{4}$, desdobrada a partir da teoria kantiana do conhecimento. Nesse importante texto inicial de sua trajetória, Benjamin defende que Kant talvez tenha sido o único, depois de Platão, a se ocupar rigorosamente em pensar a justificação do conhecimento, sendo que nas filosofias de ambos está presente "a convicção de que o conhecimento de que temos a mais pura fundamentação será, ao mesmo tempo, o mais profundo ${ }^{5}$. Portanto, a partir da reivindicação da fundamentação do conhecimento e do desenvolvimento dos seus legados teóricos ambos os filósofos fizeram justiça à exigência de que a filosofia preserve a sua profundidade investigativa, e o mesmo deveria acontecer para a filosofia vindoura que Benjamin estava propondo. Entretanto, para ele, apesar de seus avanços, a teoria kantiana conseguiu dar conta de apenas um dos lados do problema que resolveu enfrentar, que diz respeito, aos moldes das grandes filosofias que se ocupam com o universal, à afirmação de uma certeza do conhecimento que é permanente e a priori, originada na experiência, mas independente dela, e que culmina na ideia do sujeito transcendental, que é aquele que possui as condições de conhecer justamente através da experiência, de dar forma à matéria que a ele se apresenta.

\footnotetext{
4 Cf. tradução de: OLIVEIRA, 2009.

5 Cf. tradução de: OLIVEIRA, 2009. p. 202.
} 
Sabemos do impacto que considerar o papel ativo do sujeito no processo do conhecimento teve para a filosofia, mas por ora precisamos focar no outro lado do problema filosófico de Kant apontado por Benjamin, que diz respeito à experiência concebida aos moldes do lluminismo. Kant, assim como os filósofos que o precederam, não logrou conceber a experiência em sua estrutura global e singularmente temporal, pois, ao ancorar os princípios da experiência nas ciências naturais, principalmente na física newtoniana, ainda estava se baseando no conceito antigo de experiência,

cuja característica mais marcante é sua relação não apenas com a consciência pura, mas também, ao mesmo tempo, com a consciência empírica. Porém, é precisamente disso que se trata: da representação da experiência nua, primitiva e evidente que a Kant pareceu, como homem que de qualquer modo partilhou do horizonte de sua época, a única dada e até a única possível. Esta experiência, no entanto, como já indicado, era singular e temporalmente limitada e, além desta forma que compartilha de certo modo com toda experiência, esta experiência, que também poder-se-ia nomear em sentido pleno de concepção do mundo, era aquela do lluminismo. Porém, em seus traços aqui mais essenciais, ela não se distingue muito da experiência dos outros séculos dos tempos modernos. Esta foi uma das experiências ou concepções de mundo situadas no ponto mais baixo ${ }^{6}$.

Para Benjamin, conforme exprime a citação, Kant fez uso de um conceito de experiência nos mesmos moldes da tradição racionalista, ou seja, de uma noção de experiência empobrecida de significados porquanto reduzida a condições mecânico-matemáticas. Nesse sentido, conforme explica Olgária Matos, "a crítica do conhecimento pela qual Kant mostra que o sujeito do conhecimento só poderia encontrar no interior do seu objeto

\footnotetext{
6 BENJAMIN, W. Sobre o programa da filosofia vindoura. p. 203.
} 
leis que ele próprio aí inscreveu" acaba marcando "de maneira definitiva o lugar que é conveniente assinalar, segundo Benjamin, tanto o conceito de conhecimento quanto o de experiência tal como se desenvolveram ao longo do período histórico ao qual Kant pertence - a época da Aufklärung ${ }^{8 "}$. Assim, "o projeto kantiano de fundar um conhecimento puro e necessário nos limites da experiência possível se traduz na exigência da justificação de um conhecimento puro referido a uma experiência pura não empírica ${ }^{9 "}$. Entretanto, "desse ponto de vista, o conceito de 'coisa-em-si, a distinção kantiana entre intuição e entendimento apresentam-se como resíduos empíricos que abrem o caminho ao primado da lógica transcendental ${ }^{10 "}$.

Na epistemologia kantiana, a experiência é um modo de conhecer que requer entendimento, o que significa que ela sempre será determinada pelas condições de representação que possui o sujeito do conhecimento, de acordo com a sua faculdade intuitiva e com os juízos a priori de conhecimento que ele incorpora. O que decorre dessa estrutura metodológica é a restrição do conceito de experiência à afirmação autorreferente das formas apriorísticas do sujeito do conhecimento, restando destinada a figurar em seu ponto mais baixo no percurso do conhecer, por estar situada de forma descolada da complexidade que a constitui, o que é facilmente diagnosticável na linguagem e não nas certezas empíricas causais e universais. Assim, sem negar meramente a teoria kantiana, mas procurando incorporar a sua tipologia de pensamento para avançar com ela, Benjamin propõe a fundamentação de um conceito mais alto de experiência para a teoria do conhecimento. Para tanto, seria necessário conceber um conceito de conhecimento também diverso, que relacionaria o conceito de experiência à consciência transcendental e não somente empírica, tornando assim

\footnotetext{
7 MATOS, Olgária. O iluminismo visionário: Benjamin, leitor de Descartes e Kant. São Paulo: Brasiliense, 1999. p. 131.

8 MATTOS, 1999, p. 131.

9 Ibidem, p. 130.

10 Ibidem, p. 130.
} 
possível tanto a experiência mecânica quanto a experiência religiosa. Em suas palavras, "com isto não se diz de modo algum que o conhecimento torna Deus possível, e sim, que o conhecimento torna plenamente possível, em primeiro lugar, a experiência e a doutrina de Deus ${ }^{11 "}$.

Encurtando bastante o caminho que poderia nos levar a compreender o que Deus significa para Benjamin, podemos apontar que a doutrina de Deus se deixa entender neste contexto específico como algo muito próximo de uma dimensão que contempla o inexprimível, o inatingível da experiência em uma unidade de sentido que une Filosofia e Teologia e se contrapõe a um conceito de experiência restrito às determinações mecânicas e à consciência empírica, introduzindo um ponto de impossibilidade de tudo se conhecer acerca do fenômeno que se dá a conhecer. Trata-se, assim, conforme ressalta Katia Muricy, de uma proposta filosófica que "articula o conhecimento à metafísica e estabelece a sua relação, para Benjamin absolutamente necessária, com a 'totalidade concreta da experiência', com a religião e com a linguagem ${ }^{12 "}$. Desse modo, Benjamin "utiliza o termo metafísica não no sentido crítico da ciência da natureza, mas no sentido etimológico, referido às experiências para além da natureza, isto é aquelas suprarracionais, relacionadas à dimensão teológica' ${ }^{13 "}$.

Nesse sentido, de acordo com o que enfatiza Benjamin, se a filosofia se funda no fato de que na estrutura do conhecimento se situa também a estrutura da experiência para que ele se desdobre a partir dela, "esta experiência inclui pois, também a religião, a verdadeira religião, na qual nem Deus nem homem são objeto ou sujeito da experiência, porém, essa experiência funda-se no conhecimento puro e, como essência deste, a filosofia só pode e deve pensar Deus' ${ }^{14}$. Isso quer dizer que pensar Deus

\footnotetext{
1 BENJAMIN, W. Sobre o programa da filosofia vindoura. p. 209.

12 MURICY, Katia. Alegorias da dialética: imagem e pensamento em Walter Benjamin. Rio de Janeiro: Nau, 2009. p. 76.

13 Ibidem, p. 76.

14 BENJAMIN, W. Sobre o programa da filosofia vindoura. p. 214.
} 
na dimensão da experiência significa pensar a linguagem nesta esfera e, dialogando com outro de seus textos, é importante ressaltar que "no interior de toda configuração linguística reina o conflito do expresso e do exprimível com o inexprimível e a inexpressão ${ }^{15 "}$ ". Logo, "ao considerar esse conflito, vislumbra-se na perspectiva do inexprimível, simultaneamente, a última essência espiritual ${ }^{16 ”}$, isto é, a noção de Deus. A experiência para a filosofia de Benjamin será sempre uma experiência de linguagem, e o pano de fundo desta concepção é a experiência de Deus como uma essência última espiritual e linguística, e como um referencial da multiplicidade e do inexprimível que mesmo assim se comunica na linguagem e no âmbito da experiência. Por isso, para a filosofia por vir há que se considerar que "a grande reformulação e correção que devem ser empreendidas com relação ao conceito de conhecimento, orientado unilateralmente para o matemático-mecânico, somente podem ser obtidas através de uma relação do conhecimento com a linguagem ${ }^{17}$ ". Desde esse núcleo é possível vislumbrar de onde nasce a filosofia da linguagem de Benjamin, expressa principalmente nos textos "Sobre a linguagem em geral e sobre a linguagem do homem" e "A tarefa do tradutor", e que teve desdobramentos ao longo de toda a sua obra, sobremaneira em A Origem do drama trágico alemão e nas Passagens.

O tema da experiência é amplamente desenvolvido por Benjamin em muitos outros textos, inclusive em um anterior a este em que estamos nos debruçando, chamado "Experiência"18, de 1913, (1913), mas é importante enfocar aqui o caráter linguístico do conceito de experiência que Benjamin está alvitrando, atributo que permanecerá operando em todas as fases de desenvolvimento desse conceito. Com ele também surge uma teoria da

\footnotetext{
15 BENJAMIN, W. Sobre a linguagem em geral e sobre a linguagem do homem. In: BENJAMIN, W. Escritos sobre mito e linguagem (1915-1921). Trad.: Susana Kampff Lages e Ernani Chaves. São Paulo: Duas Cidades; Editora 34, 2011. p. 59.

16 Ibidem, p. 59.

17 BENJAMIN, W. Sobre o programa da filosofia vindoura. p. 208.

18 BENJAMIN, W. Erfahrung. In: Gesammelte Schriften. Band II, 1. Frankfurt: Suhrkamp, 2015. p. 54-56.
} 
tradução, inicialmente apontada no texto "A tarefa do tradutor", teoria que inclusive poderia ser compreendida de forma mais ampla e ser então elevada ao nível de qualificar a nova teoria do conhecimento proposta por Benjamin como uma teoria própria da tradução, que busca deixar transitar junto à linguagem o mundo experimentado linguisticamente. Em Benjamin, a experiência vivida poderá então ser traduzida e sempre será passível de nova tradução. Mais adiante em sua obra, quando escreve "Experiência e Pobreza" e o "O Narrador". "Considerações sobre a obra de Nikolai Leskov", momento em que diferencia experiência (Erfahrung) de vivência (Erlebnis), a teoria da experiência benjaminiana se desenvolve e se comprova - principalmente a partir dos desenvolvimentos da técnica, do isolamento do indivíduo burguês e dos fatos decorrentes da primeira guerra, fica evidente que a experiência está comprometida por ter sido atingido o seu núcleo linguístico: com o movimento do progresso em direção à catástrofe, a experiência está ameaçada porque estão afetadas as condições para que ela seja compartilhada a transmitida pela linguagem. Portanto, as experiências recaem ao nível da vivência, cujo âmbito é de outra ordem, pois na vivência a linguagem transmissível fica obliterada, favorecendo assim apenas as manifestações repetitivas do choque e do trauma. Nos textos sobre Baudelaire, devemos lembrar também, Benjamin trabalha justamente a possibilidade, através de uma poesia alegórica como a de Baudelaire, de se transformar a vivência do choque em experiência, em uma via para o conhecimento.

Retornando ao texto sobre a filosofia vindoura e à proposta de um conceito diverso de conhecimento que leve em conta um conceito mais alto de experiência, percebemos que Benjamin objetiva com isso também "eliminar a natureza de sujeito da consciência cognoscente ${ }^{19 "}$. A natureza de sujeito da consciência cognoscente provém de uma analogia com a consciência empírica, que "naturalmente" lida com os objetos diante de si. Sendo assim, a consciência cognoscente, identificada à uma natureza

19 BENJAMIN, W. Sobre o programa da filosofia vindoura. p. 206. 
subjetiva, então representa "naturalmente" os objetos da percepção do sujeito cognoscente. Conforme destaca Benjamin, é indubitável que o papel principal na teoria do conhecimento kantiana "é desempenhado pela representação, ainda que sublimada, de um eu individual, psicofísico que recebe as sensações por meio dos sentidos e sobre este fundamento forma suas representações ${ }^{20 "}$, sendo esta representação, portanto, materialização da mitologia do indivíduo moderno. Adiante, Benjamin equipara a representação às experiências mitológicas de povos primitivos que se identificam fortemente com animais e plantas de ordem sagrada e se autonomeiam a partir deles. Também compara a noção de representação às experiências de loucura, quando ocorre uma simbiose entre os objetos da percepção e a subjetividade que os percebe, restando o objeto incorporado nesta subjetividade como algo que não se diferencia mais dela. Ao fazer essas comparações, Benjamin está querendo demonstrar que, nesses moldes, a

experiência, tal como concebida em relação ao ser humano individual, psicofísico e sua consciência e, não inversamente, como especificação sistemática do conhecimento é, por sua vez, em todos os seus tipos, mero objeto desse conhecimento efetivo e, na verdade, objeto de seu ramo psicológico. Este último divide sistematicamente a consciência empírica em tipos de demência. O ser humano cognoscente, a consciência empírica cognoscente, é um tipo de consciência demente ${ }^{21}$.

Portanto, a partir daí Benjamin aventa a necessidade de a filosofia vindoura ter de se ocupar com os diferentes níveis de consciência e com os seus valores para o conhecimento, sendo que as experiências da consciência empírica devem ter valor de fantasias ou alucinações no que diz respeito à verdade, tornando assim impossível a relação objetiva entre consciência empírica e o conceito

\footnotetext{
20 Ibidem, p. 207.

${ }^{21}$ BENJAMIN, W. Sobre o programa da filosofia vindoura. p. 207.
} 
objetivo de experiência. Mesmo com essas sugestões, a pergunta acerca de "como o conceito psicológico de consciência relaciona-se com o conceito da esfera do conhecimento puro, permanece sendo um problema capital da filosofia 22". Para ir adiante na proposta de "eliminar a natureza de sujeito da consciência cognoscente", Benjamin indica que outra "tarefa central da teoria do conhecimento vindoura deve ser a de encontrar para o conhecimento, a esfera de total neutralidade com relação aos conceitos de objeto e sujeito ${ }^{23 "}$.

A separação sujeito e objeto, conforme explanada na teoria kantiana, servira até um determinado ponto para a história da filosofia, ponto esse que deveria ser transposto. Para tanto, necessário se faz partir do pressuposto de que o sujeito do conhecimento não está apartado do objeto de conhecimento que se mostra em relação na experiência, mas está intrinsecamente ligado a este objeto, que ao mesmo tempo o constitui e pelo sujeito é constituído no mundo, inseridos que estão no contexto da linguagem e da história. $\mathrm{O} a$ priori existente neste constructo benjaminiano é o mundo constituído desde sempre pela linguagem e pela história, nos termos explanados em "Sobre a Linguagem em geral e sobre a linguagem do homem" e em tantos outros textos, tratando assim de negar uma entidade metafísica de conhecimento centrada na ideia de um "eu" capaz de afirmar isoladamente a realidade na forma representacional e de dominá-la como senhorio seus objetos ou coisas. O importante aqui é entender que transpor a dualidade sujeito-objeto não significa afirmar que ela não existe, pois negar esta diferença seria o mesmo que pressupor a identidade entre uma coisa e outra, e isso é uma incongruência que levaria ao idealismo de uma ideia de linguagem pura e a todos os totalitarismos que dessa ideia poderiam advir. É importante notarmos que quando uma ideia de unidade transparece nos textos benjaminianos, sem se deixar confundir com as proposições identitárias dos idealismos subjetivos, ela se refere criticamente à imagem de um tempo irremediavelmente perdido, uma cena perdida do paraíso que se compila fragmentariamente

\footnotetext{
22 BENJAMIN, W. Sobre o programa da filosofia vindoura, p. 208.

23 Ibidem, p. 208.
} 
na mensagem dos anjos ou nas imagens dialéticas, por exemplo. Conforme explica Márcio Seligmann-Silva, "a perda da capacidade de traduzir a linguagem das coisas na linguagem dos nomes funda [...] o nascimento da pluralidade das línguas e o fim da linguagem única, do saber perfeito típico da "linguagem paradisíaca'24", sendo que essa perda resultaria da tomada de conhecimento acerca do bem e do mal conforme descrito em Gênesis, e esse tipo de conhecimento já não se baseia na ideia de Nome, mas sim na de julgamento. Motivo pelo qual "a linguagem decaída é marcada pelo fato de ser um simples meio; é signo e dela nasce a abstração" o que culmina na ideia de que "a linguagem deixa de conter apenas nomes lastrados na concretude do mundo para abarcar os elementos abstratos advindos do conhecimento do bem e do mal, da palavra julgadora ${ }^{25}$.

Deste ponto em diante podemos dar seguimento ao diálogo entre o texto inicial da filosofia vindoura pensada por Benjamin com o texto sobre a linguagem, bem como com as Passagens. Transpor a dicotomia sujeito-objeto implica não estar adstrito a esta divisão, no intuito de alcançar a dimensão da mútua determinação dialética entre uma coisa e outra, para que nenhum objeto reste relegado ao esquecimento quando integrado no discurso linguístico do conhecimento em favor da autoafirmação do sujeito. Em seu programa para a filosofia vindoura Benjamin já está interessado na ideia de que, para além de considerar o conceito de síntese kantiana, "também será altamente importante em termos sistemáticos o conceito de uma certa não-síntese de dois conceitos em um outro, pois além da síntese é possível ainda outra relação entre tese e antítese ${ }^{26 "}$. Com essa proposição, Benjamin está sustentando a possibilidade de o conhecimento trabalhar, portanto, com outras composições de pensamento que não apenas a de síntese apregoada pelo logos heterofágico. Nas Passagens, sobretudo no

24 SELIGMANN-SILVA, M. Ler o livro do mundo. Walter Benjamin: romantismo e crítica literária. São Paulo: lluminuras, 1999, p. 85.

25 Ibidem, p. 85, grifo do autor.

26 BENJAMIN, W. Sobre o programa da filosofia vindoura. p. 212. 
Konvolut N, Benjamin está se ocupando justamente em desdobrar esta ideia e em desenvolver uma epistemologia que dê conta de abordar outras novas dimensões. A premissa epistemológica lançada nas Passagens, de voltar sempre e novamente ao momento em que o negativo, o objeto rejeitado pela afirmação positiva do conhecer, opera apenas como pano de fundo opaco da positividade enaltecida pela síntese, circunscreve a chance de que esses objetos voltem a falar ao arrancá-los dali, para que, ao mesmo tempo, questionem sempre e novamente a hegemonia narcísica do sujeito de conhecimento. A própria ideia de sujeito resta, então, problematizada em conjunto com a transitoriedade dos objetos que se dão a conhecer na experiência. Uma tal ideia torna-se, portanto, um desenvolvimento da teoria do conhecimento pensada por Benjamin em "Sobre o programa de uma filosofia vindoura", que passa agora a conversar também com a dialética hegeliana e marxista. Nesse sentido, de acordo com o que sustenta BuckMorss, "se Benjamin jogou a linguagem tradicional da metafísica ocidental no quarto de depósito (junkwoom) era para resgatar a experiência metafísica do mundo objetivo, e não para ver a filosofia dissolver-se no mesmo jogo de linguagem ${ }^{27}$. Nesse mesmo sentido, Elizabeth Stewart sustenta que com "a dispersão tanto do significado de autoridade transcendental quanto o de soberania, que definem a modernidade, o mundo objetivo do sujeito, a linguagem e o conhecimento sofrem uma crise: eles estão esvaziados ${ }^{28}$ (tradução nossa). A partir disso, "para Benjamin, entretanto, esta crise tem o potencial de eventualmente transformar a relação metafísica com o mundo em uma relação materialista ${ }^{29}$.

A metafísica do mundo objetivo pensada por Benjamin através de uma relação materialista com este mundo se faz acessível através dos objetos

27 BUCK-MORSS, S. Dialética do olhar: Walter Benjamin e o projeto das Passagens. Trad.: Ana Luiza de Andrade. Belo Horizonte: Editora UFMG; Chapecó/SC: Editora Universitária Argos, 2002. p. 268.

28 STEWART, Elizabeth. Catastrophe and survival. Walter Benjamin and Psychoanalysis. Nova Iorque: Bloomsbury, 2010. p. 46.

29 STEWART, 2010, p. 46. 
que vão ficando para trás, enquanto traços ou restos que não deixam de surtir seus efeitos tanto na experiência quanto no ato cognoscente. Entendemos que, em sua teoria, esse mundo de objetos que restam constitui-se em uma dimensão outra, próxima a uma ideia de inconsciente que advém tensionando as camadas aparentemente conscientes do conhecer, do determinar e do dominar, apontando fissuras na lógica da consciência como o "natural" do agir cognoscente. Benjamin defende a necessidade de esta outra dimensão ser introduzida junto ao momento do conhecer, tanto do lado do sujeito do conhecimento quanto do lado da experiência, pois a verdade está "ligada a um núcleo temporal que se encontra simultaneamente no que é conhecido e naquele que conhece $[\mathrm{N} 3,2]^{30 "}$ Esta camada, ligada topologicamente ao ato cognoscente, se apresenta fantasmagoricamente, podemos dizer, aos moldes da teoria do inconsciente conforme concebida por Freud e Lacan. A esse respeito, o que se torna materialidade inconsciente, inscrição inconsciente, é justamente esta parte que fica registrada em negativo e esperando por leitura, que de alguma forma dará seu jeito de vir à tona em algum momento como "formação de compromisso" com este texto inscrito, inclusive e principalmente, à revelia do sujeito do conhecimento aferrado à consciência. Essa inscrição negativa ocorre na lógica do significante que, como significante, representa o sujeito para outro significante. Assim também é o entendimento de Gregor Schwering, no sentido de que "só o sujeito do significante pode representar a possibilidade de não-síntese, isto é, a incompatibilidade da consciência transcendental empírica e pura ${ }^{31 "}$ (tradução nossa), conforme queria Benjamin em seu programa para uma filosofia futura. Assim, podemos notar como a psicanálise torna-se um conhecimento crucial para a epistemologia benjaminiana exposta nas Passagens, pois será a ferramenta

\footnotetext{
3० BENJAMIN, 2018. p. 768.

31 SCHWERING, Gregor. Benjamin-Lacan; Vom Diskurs des Anderen. Wien: Turia und Kant, 1998. p. 62.
} 
necessária para sustentar uma forma de conhecer que leva em conta as múltiplas camadas de consciência e, por conseguinte, de inconsciência.

Entretanto, é importante ressaltar que antes da psicanálise tornar-se crucial para este projeto, é a teoria cabalística que está presente como base epistemológica. Conforme demonstra Buck-Morss, com o "renascimento" do pensamento cabalístico precisamente na época barroca, Benjamin viu a significação deste pensamento como "uma alternativa às antinomias filosóficas presentes não só na teologia cristã do barroco, mas no subjetivismo idealista, na forma secular da ilustração. Especificamente, o cabalismo evitava a cisão entre o espírito e a matéria ${ }^{32 ", ~ o u ~ s e j a, ~ e n t r e ~}$ sujeito e objeto. A cabala torna-se atraente para Benjamin por ser "uma forma mística de cognição que revelava verdades previamente ocultas dentro da natureza, que só enchiam de significado no contexto de uma Idade Messiânica (em termos seculares, marxistas, uma sociedade justa,

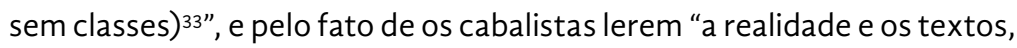
não para descobrir um plano histórico global (como na teologia hegeliano-marxista de Lukács), mas para interpretar essas partes fragmentárias como signos do potencial messiânico do presente ${ }^{34 "}$. Além disso, a verdade é acessada através de enigmas, de uma camada que resguarda um certo segredo não revelável integralmente, e essa potência de leitura da verdade operaria como uma via possível em detrimento de qualquer dogmatismo religioso. Por ocasião da escrita de Origem do drama trágico alemão, devemos atentar, a análise empreendida não é cabalística, contudo, "a cabala é a alternativa teológica oculta que orienta a crítica de Benjamin aos alegoristas barrocos cristãos35". Já no que diz respeito às Passagens, segundo Buck-Morss, é a primeira vez que a cabala é situada como estatuto paradigmático, pois Benjamin "emprega algumas de

\footnotetext{
32 BUCK-MORSS, 2002, p. 278.

33 Ibidem, p. 278.

34 Ibidem, p. 278.

35 Ibidem, p. 279.
} 
suas premissas fundamentais como modo de exegese filosófica. Isto é verdade, não apesar de, mas por causa do marxismo do projeto ${ }^{36 "}$. Talvez, conforme alerta a autora, fosse mais adequado utilizar o termo "teológico" no lugar de cabalístico, pois este termo conduziria a menos confusões. Todavia, possuindo a palavra cabala o significado de "aquilo que se recebe através da tradição ${ }^{37 "}$, e tendo ela uma relação paradoxal com o passado pelo fato de reverenciá-lo para com ele poder romper, sobretudo pela relação peculiar com a palavra estabelecida pelo pensamento cabalístico, nos parece acertada a aposta de Buck-Morss em insistir em seu uso para descrever o paradigma epistemológico benjaminiano nas Passagens, projeto esse que incorpora e performatiza os preceitos da filosofia por vir.

\section{0 conhecimento-relâmpago e o texto-trovão}

O fragmento que abre o Konvolut $N$ das Passagens é uma imagem muito elucidativa da teoria do conhecimento que Benjamin estava tentando dar forma com esse projeto: "nos domínios de que tratamos aqui, o conhecimento existe apenas em lampejos. O texto é o trovão que segue ressoando por muito tempo" $\left[\mathrm{N}_{1}, 1\right]^{38}$. Ao terminarmos de ler este fragmento, temos a sensação de termos visto uma imagem e ouvido um som, de termos tocado uma cena que habita a nossa memória e que diz respeito a uma experiência comum com a natureza que qualquer ser humano já teve - a de ver no céu se desenhar um relâmpago e de escutar o trovão que o segue. Primeiramente, esta imagem potente associada às bases epistemológicas dá a entender como está posicionado o conceito de imagem no pensamento de Benjamin, isto é, deslocado de uma ideia de imagem restrita ao domínio visual - a imagem é materialidade linguística, sonora, tátil - tem algo de sinestésico nessa proposta imagética. Através de uma imagem como essa e como

\footnotetext{
36 Ibidem, p. 279.

37 SCHOLEM, G. apud BUCK-MORSS, 2002, p. 280.

${ }^{38}$ BENJAMIN, 2018. p. 759.
} 
tantas outras que são apresentadas ao longo de sua obra é que se torna possível para ele "montar" e "apresentar" a sua teoria própria do conhecer. Sigrid Weigel inclusive sustenta que a presença marginal de Benjamin na ciência das imagens (Bildwissenschaft) diz respeito justamente ao fato de o seu pensamento por imagens lidar não especificamente com fenômenos visuais, mas com todo o tipo de imagens, de acordo com a acepção da palavra Bild em alemão (que não distingue imagem de figura, foto, quadro etc.), e de "o uso de Benjamin dessa palavra referir a um significado de Bild que precede a distinção entre imagens mentais, visuais e materiais, assim como a diferenciação entre escritura e imagem e a separação de conceito (Begriff) e metáfora"39. De tal modo, "em sua epistemologia a imagem está ligada não à representação, mas a um conhecimento (Erkenntnis) simultâneo, instantâneo, ou a um insight (Einsicht) ${ }^{40 "}$.

Retomando a imagem que abre o arquivo $\mathrm{N}$ das Passagens, podemos perceber que o conhecimento está então situado como algo que "existe apenas em lampejos", que é efêmero como o relâmpago que surge no céu, rasgando-o e anunciando o intervalo até a vinda do estrondo do trovão, bem como circunscrevendo o campo magnético e relacional entre o céu e o solo, assim como a elevada possibilidade de vinda da chuva. De tal modo, o conhecimento ainda está do lado da luz, mas esta luz não é mais uma luz que ilumina, esclarece e domina o horizonte como ocorria na Aufklärung - ela é uma luz fugidia e cortante, penetrante, como uma farpa luminosa que resta de um incêndio e que ainda assim é capaz de iluminar toda uma situação, ou como um vaga-lume que clareia a imensidão da noite, lembrando das considerações de Didi-Huberman. O conhecimento está, portanto, associado a uma imagem luminosa e passante que transpõe o horizonte: “como um vaga-lume, ela acaba por

\footnotetext{
39 WEIGEL, S. The Flash of Knowledge and the Temporality of Images: Walter Benjamin's Image-Based Epistemology and Its Preconditions in Visual Arts and Media History. Critical Inquiry 41, no. 2 (Inverno 2015). p. 344. (tradução nossa)

40 Ibidem, p. 344-345.
} 
desaparecer de nossa vista e ir para um lugar onde será, talvez, percebida por outra pessoa, em outro lugar, lá onde sua sobrevivência poderá ser observada ainda 41". Essa imagem luminosa aparece tornando simultânea uma não simultaneidade, em que o ocorrido e o agora se encontram em um instante como uma imagem, que apenas poderá ser transformada em conhecimento se articulada com a linguagem ${ }^{42}$. Assim, de acordo com Weigel, a imagem relâmpago "se torna um modo de conhecimento (Erkenntnis) que opera fora da temporalidade linear da historiografia e da narração43", ou seja, "o modo de pensar e falar em imagens conduz a uma via de conhecimento pensado como um clarão repentino que se solidifica em imagens de pensamento e em imagens linguísticas ${ }^{44 "}$. Conhecimento este que "talvez possa ser melhor caracterizado como uma faculdade na qual um "estado de espírito aumentado" (gesteigerte Geistesgegenwart) é associado a um modo involuntário de ver. A cognição lampejante é algo que acontece com a pessoa sem querer45". Portanto, essa cognição "não pretende, de forma alguma, tomar o espaço vazio dos olhos de Deus, mas situa-se precisamente em frente a ele, na posição complementar, a saber, na linha de sucessão de quem o recebe ou a quem é revelado46".

A partir desse pensamento por imagens, Benjamin está tensionando os limites da própria linguagem e, especificamente, da linguagem filosófica. Entre o lampejo e o texto-trovão, há um intervalo que instaura a possibilidade da ocorrência ou não da reflexão. Neste intervalo, muitos perigos estão a postos. Este espaço-tempo que se interpõe entre uma coisa e outra, conforme coloca Weigel, "é o tempo da latência o tempo entre o lampejo do insight e a reflexão consciente, que levanta a questão do estado de consciência na

\footnotetext{
${ }^{41}$ DIDI-HUBERMAN. Sobrevivência dos vaga-lumes. Trad. Vera Casa Nova e Márcia Arbex. Belo Horizonte: Editora UFMG, 2011. p. 119.

$42 \quad$ WEIGEL, 2015. p. 345.

43 Ibidem, p. 348.

44 Ibidem, p. 348.

45 Ibidem, p. 348.

46 Ibidem, p. 348.
} 
qual as imagens têm um papel ativo 47 ". Tempo que "pertence à latência do conhecimento que, por um longo tempo, permanece inconsciente ou pré-consciente antes das implicações histórico-teóricas do que foi visto sejam desenvolvidas e configuradas ${ }^{48}$." Weigel sugere que a latência vista na imagem poderia ser entendida a partir de um trabalho de memória que seria capaz de expor e desenvolver esta imagem ${ }^{49}$, ideia que se coaduna com o argumento que já defendemos em outra ocasião como uma ética da memória benjaminiana ${ }^{50}$, de acordo com o qual o conceito de memória involuntária exerce papel fundamental na relação com a realidade e com o ato de conhecer, uma concepção de memória inspirada em Proust, Freud e Baudelaire, e que trata de considerar como crucial a memória ligada ao inconsciente.

Este momento em que uma imagem pode ser percebida em sua fulgurabilidade é chamado por Benjamin de despertar, momento-espaço-tempo dialético em que o que se aloca é um limiar, uma zona onde as janelas do tempo se abrem e a justaposição de contrariedades podem figurar irreconciliadas em uma não síntese, como uma imagem em uma intermitência. Podemos nos perguntar, com Didi-Huberman, sobre o porquê de ser a imagem o conceito escolhido por Benjamin para dar conta deste estado de coisas ao qual ele se dedica em sua epistemologia. Com Didi-Huberman também podemos encontrar uma via de resposta: "porque na imagem o ser se desagrega: ele explode e, ao fazê-lo, mostra mas por tão pouco tempo - do que é feito. A imagem não é imitação das coisas, mas o intervalo tornado visível, a linha de fratura entre as coisas ${ }^{51 "}$. O intervalo, a fratura entre as coisas tornada visível, desloca toda a pretensão ilusória de tudo se poder conhecer. Nas palavras de Benjamin, o método de composição das Passagens "deve caracterizar e preservar os

\footnotetext{
47 Ibidem, p. 352.

48 Ibidem, p. 352.

49 Ibidem, p. 352.

50 MATTOS, M. S. Ética da memória em Walter Benjamin. Um ensaio. Porto Alegre: Bestiário, 2016.

51 DIDI-HUBERMAN, Georges. Diante do tempo: história da arte e anacronismo das imagens. Trad.: Vera Casa Nova, Márcia Arbex. Belo Horizonte: UFMG, 2015. p. 126.
} 
intervalos da reflexão[N 1, 3] $]^{52 "}$. Nesse sentido, conforme destaca Timm de Souza, "as coisas, simplesmente, nos trazem seu tempo e espaço próprios, nos trazem sua realidade com propriedade, se oferecem desde si mesmas; sua realidade pode, por seu 'aparecimento', como que criar um tempo no qual sua realidade tenha plena evidência ${ }^{53 "}$ ". O que significa compreender que "o polo principal da cognoscibilidade da coisa não está no sujeito ditador de regras, mas na intimidade da novidade 'distante, por mais próxima que ela esteja ${ }^{54}$ "'. Assim, tal realidade se torna "tão real como múltipla em seus focos de ocorrência que não dependem do aval de uma totalidade previamente dada para definitivamente existirem ${ }^{55}$. Estamos diante de uma crítica contundente ao sujeito transcendental do conhecimento. Para Benjamin, ele se desagrega diante da experiência e dos objetos, e não será mais aquele que se autoafirmará no ato de conhecer.

Assim, se há um intervalo tornado visível, estamos diante do tempo. E o que é possível fazer diante desta visibilidade? É possível operar com a linguagem em seu sentido lato, nos diz Benjamin. A filosofia, dentre outras coisas, é um trabalho próprio com a linguagem, com a crise, a construção e a desconstrução de sentidos. Conforme propõe Benjamin, a escrita filosófica precisa atuar com as imagens até o ponto de também se tornar escrita imagética. Se, na imagem de abertura do arquivo epistemológico das Passagens, somos alertados de que o texto é o trovão que segue ressoando por muito tempo depois da imagem-relâmpago, sabemos desde logo que este muito tempo não é sinônimo de eternidade petrificada, mas é algo da ordem da transitoriedade. O próprio texto tem a característica efêmera da imagem - ele também se evanesce para um tempo presente e pode retornar, ser retomado, relido sincronicamente

\footnotetext{
52 BENJAMIN, 2018. p. 760.

53 SOUZA, Ricardo Timm de. Adorno \& Kafka: paradoxos do singular. Passo Fundo: IFIBE, 2010.

p. 75. Grifo do autor.

54 Ibidem, p. 75, grifo do autor.

55 Ibidem, p. 75, grifo do autor.
} 
por temporalidades distintas. $\mathrm{O}$ a posteriori do conhecimento, o momento da reflexão, do nachdenken, também se torna imagem e por isso possui índice histórico de legibilidade. Nesse sentido é que Benjamin atenta para o fato de ser necessário, para o projeto das Passagens, "não renunciar a nada que possa demonstrar que a representação materialista da história é imagética [bildhaft] num sentido superior que a representação tradicional" $[\mathrm{N} 3,3]$. Isso quer dizer, pois, que a própria representação deverá ser imagética para os fins desta teoria do conhecimento. Nas palavras de Weigel, "o caráter a posteriori da reflexão em relação à imagem é igualmente expresso na imagem do longo trovão, que representa a reflexão linguisticamente constituída literalmente na palavra alemã nachdenken (o que significa 'pensar depois' e 'refletir') 56", bem como "na caracterização da epistemologia de Benjamin como Bilddenken [pensar por imagens] ${ }^{57 "}$.

A respeito da epistemologia benjaminiana, Buck-Morss aponta precisamente: "sem a teologia (eixo da transcendência) o marxismo cai no positivismo; sem o marxismo (eixo da história empírica) a teologia cai na magia ${ }^{58}$. Portanto, este pensamento por imagens concebe a imagem dialética como conceito-chave, sendo que com essas imagens, "na 'encruzilhada entre a magia e o positivismo', [...] ambos os caminhos são negados e ao mesmo tempo dialeticamente superados ${ }^{59}$ ". Assim, Benjamin reconhece que o problema, conforme ressaltou em muitos momentos, principalmente em cartas, seria a construção dessa filosofia que trata de tais dimensões dialeticamente. Como elaborar essa construção, conforme questiona Buck-Morss, "se a substância das imagens dialéticas devia se encontrar nos objetos cotidianos e nos textos profanos, como deviam

\footnotetext{
56 WEIGEL, 2015. p. 366.

57 Ibidem, p. 366.

58 Ibidem, p. 298.

59 Ibidem, p. 298.
} 
estes ser contextualizados para que seu significado teológico (ou seja, filosófico-político) pudesse ser reconhecido?60".

Benjamin se dedicou incansavelmente ao projeto das Passagens, tentando colocar em prática esta forma-conteúdo diversa de construção do conhecimento já na metodologia de trabalho, inaugurando uma configuração particular de arquivamento dos materiais e de cesura da escrita. $\mathrm{O}$ componente visual já estava presente na forma de escrita dos manuscritos, na caligrafia minúscula, nos códigos coloridos, no modo de divisão, dobra e uso como um todo do papel - matéria sem a qual, em sua época, não se podia escrever. Em outro fragmento do arquivo $N$, registrou: "meu pensamento está para a teologia como o mata-borrão está para a tinta. Ele está completamente embebido dela. Mas se fosse pelo mata-borrão, nada restaria do que está escrito ${ }^{611}[\mathrm{~N} 7,7]$. Com esta nota, Benjamin está sugerindo que a teologia estaria presente de ponta a ponta no projeto das Passagens, mas de forma "quase" invisível (essa observação também está presente na primeira tese de Teses sobre o conceito de história). BuckMorss sustenta que Benjamin elegeu "essa estratégia por medo de que esse modo de expressão terminasse trazendo de volta o significado da 'nova' natureza ao particularismo religioso ${ }^{62}$ " de modo que "essa natureza movesse a teologia para fora da superestrutura ideológica, trazendo-a ao domínio da política secular63". Ao lermos as Passagens entramos em contato com a dimensão teológica invariavelmente, e sabemos disso mais pelas pistas e pelos efeitos causados no pensamento pela leitura do que pela quantidade de categorias teológicas que ali porventura estejam sendo trabalhadas em primeiro plano. É o caso de quando nos deparamos com o anãozinho corcunda, por exemplo, aquele ser fantasmático que nos devolve um olhar em momentos cruciais dos textos benjaminianos,

\footnotetext{
60 Ibidem, p. 298.

61 BENJAMIN, 2018. p. 780.

62 BUCK-MORSS, 2002. p. 298.

63 BUCK-MORSS, 2002. p. 298.
} 
ou no caso em voga em que estamos diante de uma imagem que fala do lampejo e do trovão e de, com ela, de fato podermos visualizar e tatear a dimensão transcendental atinente ao conhecimento e à experiência.

\section{Imagem dialética}

O percurso enfrentado até aqui requer que penetremos na compreensão da imagem dialética, conceito que, dentre outras coisas, expõe a dialética do experienciar e do conhecer. Este é um dos conceitos centrais de todo o projeto das Passagens, e sem o entendimento aprofundado dele não é possível apreender o sentido desse projeto filosófico. No Konvolut $N$, onde estão lançadas as teses epistemológicas do projeto, a imagem dialética aparece em diferentes fragmentos, inserida em um contexto de valorização da visualidade ao lado do método marxista pelos fragmentos que os antecedem. A primeira conceituação é a que segue:

Não é que o passado lança sua luz sobre o presente ou que o presente lança sua luz sobre o passado; mas a imagem é aquilo em que o ocorrido encontra o agora num lampejo, formando uma constelação. Em outras palavras, a imagem é a dialética na imobilidade. Pois, enquanto a relação do presente com o passado é puramente temporal e contínua, a relação do ocorrido com o agora é dialética - não é uma progressão, e sim uma imagem, que salta. - Somente as imagens dialéticas são imagens autênticas (isto é: não-arcaicas), e o lugar onde as encontramos é a linguagem. Despertar. $[\mathrm{N} \mathrm{2a}, 3]^{64}$.

Observamos, então, que a primeira entrada no conceito mostra que não podemos incorrer em erro e tentar entender a dimensão temporal da imagem dialética a partir de suposições que considerem o tempo ao modo

64 BENJAMIN, 2018. p. 767. 
cronológico tradicional, linear e contínuo, no sentindo de que o passado estaria lançando sua luz sobre o presente para iluminá-lo como que avançando na linha do tempo, ou, então, que o presente lançaria o seu foco luminoso para o passado buscando encontrá-lo, como uma volta na linha do tempo. A imagem é algo de outra ordem, que diz respeito à relação entre o ocorrido (o fato que passou) e o agora (o instante presente), e que surge em um lampejo que, ao cintilar, forma uma constelação. O ocorrido de fato encontra o agora por uma sincronia que é estranha à linearidade cronológica, pois não possui relação de causalidade com o agora, mas sim relação dialética. Ele deixa de ser um fato passado para se tornar um fato presente, na dinâmica da atualização - se torna atual, na forma de imagem. Uma imagem que também é imagem da própria dialética, que nunca deixa de ser movimento, mas que em um dado momento deixa-se capturar imobilizando-se em uma imagem saturada de tensões, e tal captura pode se dar no instante presente ou pode ter se dado no passado, tornando-se o agora um instante de revelação. $O$ intento de Benjamin é focar, com a imagem dialética, a relação dialética entre o ocorrido e o agora, ou seja, o ponto em que algo que passou quebra a continuidade do tempo cronológico e da repetição da história, abrindo as portas para o tempo messiânico, onde tudo o que daí advém se torna tempo para a apocatástase. Didi-Huberman é preciso quando diz, em seu livro Diante do tempo. História da arte e anacronismo das imagens: "sempre, diante da imagem, estamos diante do tempo65".

Buck-Morss argumenta que o tempo existe em dois registros nesse conceito. O primeiro é o tempo dos acontecimentos que se dão em um continuum, da história secular e da catástrofe, que caracterizam o tempo humano não realizado. O segundo, é o tempo revolucionário, onde cada tempo-agora (Jetztzeit) é uma chance de antecipação da redenção, da

65 DIDI-HUBERMAN, G. Diante do tempo: história da arte e anacronismo das imagens. Trad.: Vera Casa Nova, Márcia Arbex. Belo Horizonte: UFMG, 2015. p. 15. 
vinda do tempo messiânico ${ }^{66}$. É importante compreendermos, conforme afirma Gagnebin valendo-se do "Fragmento teológico-político" escrito por Benjamin, que "o Messias só virá no momento em que tiver se tornado dispensável. Ele não vem para instaurar seu reino [...]. O Messias chega, portanto, quando sua vinda se realizou tão integralmente que o mundo já não é profano nem sagrado, mas liberto ${ }^{67}$ ". Assim, em Benjamin, a vinda do tempo messiânico é também realização da felicidade terrestre, "não porque fé religiosa e convicções políticas atuariam no mesmo sentido e em direção à mesma meta (telos), mas porque a atualidade messiânica não se pode enunciar a não ser na prosa liberta, livre, do mundo terrestre ${ }^{68 "}$.

A proposta benjaminiana de a imagem ser a "dialética na imobilidade" (Dialetik im Stillstand) costuma ser objeto de muito debate. Com esse construto teórico, Benjamin está defendendo ser possível apreendermos fragmentos da verdade em uma estrutura do conhecer que leva em conta a redenção da própria experiência, dos objetos históricos que se mostram em relação nessa experiência, e para isso eles precisam ser olhados e salvos no ato de conhecer. Eis o primeiro princípio de sua doutrina (Lehre) do materialismo histórico que está aventando: "um objeto da história é aquele em que o conhecimento se realiza como sua salvação69" [N 11, 4]. Nesse sentido, para serem olhados e salvos, é necessário pressupor que "ao pensamento pertencem tanto o movimento quanto a imobilização dos pensamentos ${ }^{70 "}[\mathrm{~N} 10 \mathrm{a}, 3]$, e onde o pensamento "se imobiliza numa

66 BUCK-MORSS, 2002. p. 290. Notemos os termos com os quais Benjamin termina suas teses "Sobre o conceito de história", dizendo que mesmo diante da proibição especulativa sobre o futuro, "nem por isso o futuro se converteu para os judeus num tempo homogêneo e vazio. Pois nele cada segundo era a porta estreita pela qual podia penetrar o Messias". BENJAMIN, W. Teses sobre o conceito de história. In: Magia e técnica, arte e política: ensaios sobre literatura e história da cultura. p. 232.

67 GAGNEBIN, J. M. Limiar, aura e rememoração. São Paulo: Editora 34, 2014. p. 192.

68 Ibidem, p. 192.

69 BENJAMIN, 2018. p. 788-789.

70 Ibidem, p. 788. 
constelação saturada de tensões, aparece a imagem dialética ${ }^{71 "}$ [N 10a, 3]. É essa situação de maior tensão entre os opostos dialéticos que deve ser buscada pelo conhecimento, pois é onde a dialética se revela ao materialista histórico como não concluída e mais próxima à verdade, pois está paralisada, para esse observador, em um contexto ainda não reconciliado para aquele que se investe na posição do conhecer, onde apesar de opostos os objetos podem configurar uma mesma cena. Neste contexto de indecidibilidade, onde as diferenças ainda não foram subsumidas, a dialética se paralisa em uma imagem por um instante, e é esta imagem fulgurante que precisa ser apreendida e apresentada, preservando a sua característica essencial de continuar sendo imagem. Benjamin não está defendendo, portanto, que a dialética é imóvel. Ao contrário, é o pensamento que se imobiliza, e para que a dialética seja compreendida na plenitude de seu movimento, se faz necessário apreendermos os momentos onde o maior volume de opostos se reúnem em uma imagem, para que assim a dialética privilegie a sua capacidade de lidar com as diferenças e se mantenha aberta para renovação. Assim, conforme registrou Adorno, o filosofar de Benjamin "tem o olhar da Medusa", e a sua dialética se torna "prefigurada no quid pro quo do mais rígido com o mais móvel72", considerando, sobretudo, que a própria imagem que se paralisa é ruinante, transitória, e, mesmo sob o olhar da Medusa, evanesce.

$O$ fragmento seguinte a este que delineia o conceito de imagem dialética é uma anotação em que Benjamin assinala que, após estudar o conceito de verdade de Goethe em Simmel, ficou claro para ele que o conceito de origem (Ursprung) trabalhado por ele em Origem do drama trágico alemão se trata de "uma transposição rigorosa e concludente deste conceito goethiano fundamental do domínio da natureza para aquele da história. Origem - eis o conceito de fenômeno originário transposto

\footnotetext{
71 Ibidem, p. 788.

72 ADORNO, T. W. Caracterização de Walter Benjamin. In: sociedade. São Paulo: Editora Ática, 1998. p. 228.
} Prismas. Crítica cultural e 
do contexto pagão da natureza para os contextos judaicos da história范" [N 2a, 4]. Registra, a seguir, que no projeto das Passagens também está empreendendo um estudo das origens, sendo as passagens parisienses a imagem decisiva desta investigação. Seu intuito é perseguir a origem das formas e as transformações das passagens até o seu ocaso, tornando-se fenômenos originários para o seu pensamento "quando, em seu próprio desenvolvimento - um termo mais adequado seria desdobramento - $\mathrm{fa}$ zem surgir a série das formas históricas concretas das passagens, assim como a folha, ao abrir-se, desvenda toda a riqueza do mundo empírico das plantas ${ }^{74 "}[\mathrm{~N} 2 \mathrm{a}, 4]$. As passagens parisienses são monumentos de um não mais-ser, são as ruínas de um sonho de progresso e que, em sua ruinância, configuram uma imagem, uma chance única de interpretação histórica. Esta imagem se apresenta ao mesmo tempo como imagem de um sonho de progresso e como imagem da ruína deste sonho, assim como da transitoriedade ou do deperecimento da matéria, da experiência e do conhecimento, e, ainda, como imagem da catástrofe, que é reproduzida incansavelmente pelo movimento do progresso. Considerar as passagens parisienses como fenômenos originários significa levar a sério o conceito de origem lançado já na sinopse de Origem do drama trágico alemão, isto é, implica que se entenda que origem não tem nada que ver com gênese, como se o nascimento ou o surgimento do fenômeno fosse compreendido a partir desse momento. " $O$ conceito de origem não se refere ao devir de algo que nasce, mas antes a algo que emerge do processo de devir e esgotamento. A origem está no rio do devir e o seu ritmo arrasta para a torrente os materiais da gênese ${ }^{75}$. Desse modo, aquilo que advém de uma noção de "origem nunca se dá a conhecer no inventário nu e óbvio do fatual, e o seu ritmo abre-se a uma dupla perspectiva ${ }^{76 "}$ ", sendo que "esta pede, por um

\footnotetext{
73 BENJAMIN, 2018. p. 767.

74 Ibidem, 767.

75 BENJAMIN, W. Origem do drama trágico alemão. Belo Horizonte: Autêntica Editora, 2011. p. 257.

76 Ibidem, p. 257.
} 
lado, para ser reconhecida como restauração, enquanto reconstituição, e por outro lado, nesse contexto, como algo que é imperfeito e inacabado ${ }^{77 "}$. Por isso, as ruínas das passagens parisienses, figurando na cidade de Paris como um fantasma dos ideais do progresso - como algo que ainda está lá e opera como testemunho de um processo de devir e esgotamento - puderam ser compreendidas como fenômenos originários no contexto em que Benjamin se encontrava justamente por não terem ligação causal direta com o momento histórico em que vivia, e ainda assim serem sincrônicas com a sua época - poderiam ser compreendidas em sua época. Pois, pela performatização de sua derrocada ainda no início do séc. XX, as passagens Ihe permitiram antever o ocaso da própria Europa, dos ideais civilizatórios e humanistas de um certo modelo de pensamento filosófico. O tempo do progresso só produz ruínas - é o império não passageiro da barbárie. Por isso o tempo messiânico precisa poder ser acessado, e sua via de acesso são as imagens dialéticas, tais como as passagens de Paris.

As imagens dialéticas são autenticamente históricas, e o objeto histórico, para Benjamin, é aquele que salta do continuum da história linear para, ao se agrupar com demais objetos do presente, configurar novas imagens da história. Assim, as imagens não podem ser arcaicas, no sentido da entificação de uma essência, de algo que já existe como uma espécie de modelo ao qual se deve retornar, a partir de um acontecimento que é já apropriação. Benjamin sustenta que o método das Passagens não almeja o retorno e o enaltecimento dos arcaísmos, da mitologia. Essa volta sequer é possível. Com o seu método, ele propõe que a busca seja pelo tempo autenticamente histórico, através de imagens ruinantes, caminho que pode ser "comparável ao método da fissão nuclear - [que] libera as forças gigantescas da história que ficam presas no 'era uma vez' da narrativa histórica. A historiografia que mostrou 'como as coisas efetivamente aconteceram', foi o narcótico mais poderoso do século ${ }^{78 "}\left[\mathrm{~N}_{3}, 4\right]$. Assim, Benjamin não

\footnotetext{
77 Ibidem, p. 257.

78 BENJAMIN, 2018. p. 769.
} 
busca o retorno e a identificação com imagens arcaicas (míticas), mas procura, através das imagens que se apresentam dialeticamente como restos e não como entidades arcaicas e totais, liberar a força histórica contida nelas - e essa força é a da dialética, dialética do despertar para o que sobra, para os restos. Com o despertar deste estado narcótico que crê ser possível chegar nas coisas como elas de fato foram, em suas essências, a força verdadeiramente histórica é liberada através da leitura das imagens dialéticas, que se sincronizam com o tempo agora não para recairmos na mitologia e enaltecermos o passado perpetuando-o, mas para recontarmos a história apresentando essas imagens que se atualizam em uma nova via de rememoração e interpretação que rompa com a repetição da catástrofe.

\section{Considerações finais: sujeito em desagregação}

O século XX foi marcado pela profusão de filosofias que preconizam a problematização da categoria de sujeito do conhecimento, tais como as filosofias de Walter Benjamin, Theodor Adorno, Michel Foucault e Jacques Derrida, para citar apenas alguns exemplos. Em um caminho muito próximo também seguia curso a psicanálise, que com a investigação do inconsciente chega à conclusão de que o eu, essa entidade imaginária da consciência, não é mais, segundo cunhou Freud, senhor de sua própria casa. A teoria lacaniana do sujeito do inconsciente concebe um sujeito dividido, faltante, que só pode ser pensado nas trilhas de um sujeito por vir. Sabemos que o movimento que culmina neste tipo de crítica provém de outros tempos, mas as vivências às quais ficou exposta a cultura ocidental do início do século XX foram determinantes para a concatenação e a abundância de pensamentos críticos como os citados.

Segundo Ricardo Timm de Souza, a cultura ocidental do século que nos antecedeu esteve "às voltas, em suas múltiplas facetas, com um fato dado, a precipitação do processo de rompimento e desagregação de uma Totalidade 
fática de sentido79". O filósofo nos mostra que acontecimentos como Auschwitz, Hiroshima, desmatamento da Amazônia, chacina da Candelária e o assassinato de Martin Luther King, dentre tantos outros fatos, muitas vezes inomináveis, e que ainda seguem acontecendo de forma igualmente catastrófica, como os assassinatos de Marielle Franco, Amarildo Dias de Souza, Claudia Silva Ferreira, Mestre Moa do Katendê, nos mostram que "a estas alturas, não se pode mais julgar que tais fatos sejam meros acidentes de percurso de um trofismo sadio: eles são, em verdade, expressões do real metabolismo interno da Totalidade, ou do que tem restado dela ${ }^{80}$. A pressuposição de um sujeito do conhecimento aos moldes em que se erigiu a filosofia, principalmente depois de Kant, apesar dos avanços em termos diagnósticos acerca do processamento do conhecimento, baseou-se nesta ideia de unidade de sentido que entrou em colapso no início do século XX. Kant estabeleceu que existe o saber a posteriori, ligado à experiência e aos objetos, e um saber que, digamos assim, antecede a experiência, um saber a priori que não depende da experiência e que inclusive é o que a torna possível - saber que é a própria ideia de sujeito cognoscente: "no conhecimento a priori nada pode ser atribuído aos objetos que o sujeito pensante não extraia de si próprio ${ }^{81}$. Entretanto, as experiências que apontamos anteriormente demonstram que é justamente esta estrutura subjetiva que pretensamente tornaria possível a experiência que foi capaz de articular racional e ardilosamente tais eventos. São, conforme apontou Timm de Souza, expressões reais do metabolismo interno da Totalidade. Diante disso, "à desagregação interna de todo um sistema de sentido e de valores, necessita corresponder um modelo de inteligibilidade para além

79 SOUZA, Ricardo Timm de. Totalidade \& desagregação. Sobre as fronteiras do pensamento $e$ suas alternativas. Porto Alegre: EDIPUCRS, 1996. p. 27.

8o Ibidem, p. 27.

81 KANT, Immanuel. Crítica da razão pura. 5. ed. Trad.: Manuela Pinto dos Santos e Alexandre Fradique Morujão. Lisboa: Calouste Gulbenkian, 2001. Paginação na edição original KrV, B XXIII. KANT, I. Kritik der reinen Vernunft. Hamburg: Feliz Meiner, 1998. 
da subserviência à tradição em falência ${ }^{82 "}$. Citando as filosofias de Franz Rosenzweig e Emmanuel Levinas, e articulando-as com os conteúdos mais radicais da teoria crítica, Souza aponta para um dos caminhos possíveis de desconstrução de tal modelo hegemônico, procurando intervalar o curso da subserviência da experiência aos sistemas falidos de pensamento, subsidiados pela lógica mítica identitária entre a não identidade e a identidade, para cuja desconstrução torna-se necessário descentrar a ontologia da sua posição de prima philosophia, deixando ruir os jogos mais astuciosos de neutralização da diferença, levando às últimas consequências "o dèbâcle que a própria ideia de subjetividade se auto-impôs ao procurar nela mesma e não mais que nela mesma - em sua auto-produção auto-referenciada - seu último fundamento ${ }^{83}$. Trata-se de colocar em questão os esquematismos compreensivos, consoladores e conciliadores das filosofias das essências e das existências e seu próprio estatuto de racionalidade estruturado desde a identificação entre ser e pensar. Fora do alcance do representável, ética e estética tornam-se vias de acesso à construção de sentidos não totalizantes, capazes de suportar a anterioridade e multiplicidade radical da diferença, consubstanciando-se na "condição para a percepção de um futuro que traga em si mais do que o resultado da pulverização de um universo de sentido ${ }^{84 "} \mathrm{e}$ que não esteja adstrito à percepção, mas sim levado de fato à ação, à prática, seja da escrita, seja da coleção, da montagem ou da escuta, em direção ao desencontro consigo mesma, ao novo, ao outro propriamente encontrado.

Ao olharmos para a filosofia de Benjamin como um todo, não podemos encontrar momentos em que apenas um horizonte de sentido esteja sendo perscrutado. Sua obra é um constante exercício de abertura à multiplicidade de sentidos, por isso a sua busca incessante em desbancar as categorias

\footnotetext{
82 SOUZA, 1996. p. 27.

83 SOUZA, R. T. S. Fenomenologia e metafenomenologia: substituição e sentido - sobre o tema da "substituição" no pensamento ético de Levinas. In: SOUZA, R. T.; OLIVEIRA, N. F. (org.) Fenomenologia Hoje: existência, ser e sentido no alvorecer do século XXI. Porto Alegre: EDIPIUCRS, 1999. p. 395.
}

84 SOUZA, 1996. p. 27. 
de pretensa segurança em filosofia. Mesmo sendo a busca pela forma da verdade um de seus principais lemas, desde o início a concebe como inexprimível - entende o trabalho filosófico como esse constante movimento em terrenos instáveis. Já na sua juventude, conforme demonstramos neste artigo, Benjamin percebeu que para fazer falar o inexprimível da verdade, precisaria atacar as estruturas tradicionais do conhecimento. As vivências às quais estava exposto em seu contexto histórico permitiram-Ihe detectar que se elas são degradantes e desagregadoras, comprometendo assim a própria existência da experiência, a subjetividade cognoscente também está em desagregação. Não é mais possível filosofar sem perfazer a crítica radical à Totalidade não verdadeira. Tornando-se o sujeito de conhecimento e as coisas submetidos à fragmentação, assim também deverá corresponder uma filosofia por vir em fragmentos. Com as Passagens, Benjamin está entregue a esse desejo, que também é mortífero.

\section{Referências}

ADORNO, T. W. Caracterização de Walter Benjamin. In: ADORNO, T. W. Prismas. Crítica cultural e sociedade. São Paulo: Editora Ática, 1998. p. 223-237. BENJAMIN, W. Erfahrung. In: Gesammelte Schriften. Band II, 1. Frankfurt: Suhrkamp, 2015. pp 54-56.

BENJAMIN, W. Gesammelte Schriften. v. 2. Frankfurt am Main: Suhrkamp, 1991, p. 1090-1091.

BENJAMIN, W. Origem do drama trágico alemão. Belo Horizonte: Autêntica Editora, 2011.

BENJAMIN, W. Passagens. Belo Horizonte: UFMG, 2018. p. 762-763.

BENJAMIN, W. Sobre a linguagem em geral e sobre a linguagem do homem. In: BENJAMIN, W. Escritos sobre mito e linguagem (1915-1921). Trad. Susana Kampff Lages e Ernani Chaves. São Paulo: Duas Cidades; Ed. 34, 2011. https:// doi.org/10.1590/s2316-40182012000200017

BENJAMIN, W. Über das Programm der kommenden Philosophie. In: Gesammelte Schriften. Band II, 1. Frankfurt: Suhrkamp, 2015. p 157-171. 
BUCK-MORSS, S. Dialética do olhar: Walter Benjamin e o projeto das Passagens. Trad. Ana Luiza de Andrade. Belo Horizonte: Editora UFMG; Chapecó/SC: Editora Universitária Argos, 2002.

DIDI-HUBERMAN, G. Diante do tempo: história da arte e anacronismo das imagens. Trad. Vera Casa Nova, Márcia Arbex. Belo Horizonte: UFMG, 2015. DIDI-HUBERMAN, G. Sobrevivência dos vaga-lumes. Trad. Vera Casa Nova e Márcia Arbex. Belo Horizonte: Editora UFMG, 2011.

GAGNEBIN, J. M. Limiar, aura e rememoração. São Paulo: Editora 34, 2014. https://doi.org/10.34024/limiar.2016.v3.9237

KANT, I. Crítica da razão pura. 5. ed. Trad. Manuela Pinto dos Santos e Alexandre Fradique Morujão. Lisboa: Calouste Gulbenkian, 2001. Paginação na edição original KrV, B XXIII. KANT, I. Kritik der reinen Vernunft. Hamburg: Feliz Meiner, 1998. https://doi.org/10.1524/9783050050386.5

MATOS, O. O iluminismo visionário: Benjamin, leitor de Descartes e Kant. São Paulo: Brasiliense, 1999.

MATTOS, M. S. Ética da memória em Walter Benjamin: Um ensaio. Porto Alegre: Bestiário, 2016.

MURICY, K. Alegorias da dialética: imagem e pensamento em Walter Benjamin. Rio de Janeiro: Nau, 2009.

OLIVEIRA, E. V de. Um mestre da crítica: Romantismo, Mito e lluminismo em Walter Benjamin. 2009. 216f. Tese (Doutorado em Filosofia) - Faculdade de Filosofia, Letras e Ciências Humanas da Universidade de São Paulo, São Paulo, 2009. https://doi.org/10.11606/t.8.2009.tde-22022010-164542

SCHWERING, Gregor. Benjamin-Lacan; Vom Diskurs des Anderen. Wien: Turia und Kant, 1998. p. 62.

SELIGMANN-SILVA, M. Ler o livro do mundo. Walter Benjamin: romantismo e crítica literária. São Paulo: Iluminuras, 1999. p. 85.

SOUZA, Ricardo Timm de. Adorno \& Kafka: paradoxos do singular. Passo Fundo: IFIBE, 2010.

SOUZA, Ricardo Timm de. Totalidade \& desagregação. Sobre as fronteiras do pensamento e suas alternativas. Porto Alegre: EDIPUCRS, 1996. 
SELIGMANN-SILVA, M. Fenomenologia e metafenomenologia: substituição e sentido: sobre o tema da "substituição" no pensamento ético de Levinas. In: SOUZA, R. T.; OLIVEIRA, N. F. (org.). Fenomenologia Hoje: existência, ser e sentido no alvorecer do século XXI. Porto Alegre: EDIPIUCRS, 1999. https:// doi.org/10.15448/1984-6746.2004.4.34698

SELIGMANN-SILVA, M. Totalidade \& desagregação: sobre as fronteiras do pensamento e suas alternativas. Porto Alegre: EDIPUCRS, 1996.

STEWART, E. Catastrophe and survival: Walter Benjamin and Psychoanalysis. Nova lorque: Bloomsbury, 2010. p. 46. Tradução livre.

WEIGEL, S. The Flash of Knowledge and the Temporality of Images: Walter Benjamin's Image-Based Epistemology and Its Preconditions in Visual Arts and Media History. Critical Inquiry 41, n. 2, p. 344-366, Inverno 2015. https:// doi.org/10.1086/679079

\section{Endereço postal}

\section{Manuela Sampaio de Mattos}

Av. Caçapava 272/502.

Bairro Petrópolis.

CEP 90460-130. Porto Alegre, RS, Brasil. 